\title{
Uma prática pedagógica apoiada na construção de infográficos para o ensino e aprendizagem de estereoquímica
}

\author{
Aline Grunewald Nichele - IFRS - Campus Porto Alegre, \\ aline.nichele@poa.ifrs.edu.br, https://orcid.org/0000-0001-6177-2037 \\ Kênya Silva dos Santos Moraes - IFRS - Campus Porto Alegre, \\ kenyassmoraes@gmail.com, https://orcid.org/0000-0002-5393-4267 \\ Fabiane Nunes da Silva - IFRS - Campus Porto Alegre, \\ fabianenunesdasilva98@gmail.com, https://orcid.org/0000-0003-2972-2763
}

\section{RESUMO}

Infográficos têm sido usados como um recurso para o ensino e aprendizagem. A criação de infográficos pelos estudantes estimula-os a encontrar e avaliar as informações, além de desafiá-los a apresentar essas informações de forma criativa, contribuindo para o aprendizado do tema em estudo. Nesse contexto, criamos uma prática pedagógica para ensino e aprendizagem de Química a ser aplicada no contexto da sala de aula presencial ou virtual, envolvendo o estudo da atividade ótica, tema que compõe os estudos de isomerismo e estereoquímica. Pretendendo-se melhorar a prática, considerando conjuntamente a planificação, a ação e a (auto)reflexão, essa estratégia constituiu-se numa pesquisa-ação. Neste artigo, relatamos a criação da prática pedagógica sobre atividade ótica envolvendo a produção de infográficos. A prática pedagógica foi aplicada a estudantes de disciplina de Química Orgânica composta por licenciandos da área de Ciências da Natureza. A avaliação da aprendizagem sobre o tema "atividade ótica", no âmbito dos estudos da estereoquímica, foi realizada por meio de uma atividade na plataforma Kahoot, na qual os estudantes utilizaram os infográficos construídos como material de referência.

Palavras-chaves: Ensino e aprendizagem de química, infográfico, atividade ótica.

\section{A pedagogical practice supported by the creation of infographics for teaching and learning stereochemistry}

\begin{abstract}
Infographics have been used as a resource for teaching and learning. The creation of infographics by students encourages them to find and evaluate information, in addition to challenging them to present this information in a creative way, contributing to the learning of the topic under study. In this context, we created a pedagogical proposal for teaching and learning Chemistry, involving the study of optical activity, a topic that makes up the studies of isomerism and stereochemistry. Intending to improve the practice, considering together planning, action and (self) reflection, this strategy constituted an actionresearch. In this paper, we report the creation of the pedagogical proposal on optical activity involving the creation of infographics. The pedagogical proposal was applied in an Organic Chemistry class composed of pre-service teacher undergraduates in the Natural Sciences. The evaluation of learning on the topic "optical activity", within the studies of stereochemistry, was carried out through an activity on the Kahoot platform, in which students used the infographics built as reference material.
\end{abstract}


Keywords: Teaching and learning chemistry, infographic, optical activity.

\title{
1 INTRODUÇÃO
}

As práticas pedagógicas são o "cotidiano do professor na preparação e execução de seu ensino" (CUNHA, 1988, p. 94). A maior presença das tecnologias digitais (TD) e a emergente demanda de adaptação das instituições de ensino para minimizar os impactos das restrições nas atividades educacionais por conta da pandemia de COVID-19, desafiam os professores a reconfigurarem suas práticas pedagógicas. $\mathrm{O}$ primeiro movimento de adaptação para mitigar os impactos da restrição de acesso ao ambiente escolar foi a adoção do ensino remoto, que se caracteriza pela transposição do ensino presencial físico - mesmo curso, currículo, metodologias e práticas pedagógicas - para os meios digitais. Nesta situação as TD não foram usadas para a mudança da prática; em encontros síncronos e assíncronos, hardwares e softwares foram meras ferramentas deste processo.

Em outra perspectiva tem-se a educação digital, a qual não se restringe à adoção de softwares, hardwares e redes de comunicação. A educação digital implica na adoção de práticas pedagógicas mais dinâmicas que promovam a apropriação e a atribuição de significado da temática estudada, bem como o desenvolvimento de competências específicas no âmbito do ensino e da aprendizagem na perspectiva da transformação digital (MOREIRA; SCHLEMMER, 2020).

\begin{abstract}
A educação digital contempla práticas pedagógicas com diferentes níveis de adoção de tecnologias, desde a educação presencial apoiada por TD, bem como a educação híbrida e, numa perspectiva de processos educacionais completamente em rede, a educação online (NICHELE; CANTO, 2020, p. 561).
\end{abstract}

A produção de materiais educacionais multimídia é um importante recurso para o desenvolvimento de práticas pedagógicas no contexto da educação digital; infográficos têm características que tornam seu uso educacional apropriado e recomendado. Uma das vantagens do uso educacional de infográficos é a autoria, em especial à baixa complexidade requerida para a produção destes.

Infográficos são representações visuais de informações, das mais simples às mais complexas. O conteúdo de infográficos pode conter texto, figuras a ilustrações estilizadas a animações de dados interativas complexas. Um infográfico precisa transmitir uma mensagem ao leitor, de forma clara e em uma linguagem adequada ao seu públicoalvo, levando em consideração que diferentes usuários utilizam diferentes estratégias para interpretar e aprender sobre o material representado nos infográficos.

A criação de infográficos aumenta o engajamento dos estudantes nas aulas, servindo como recurso para o ensino e aprendizagem de Química (KOTHARI et al., 2019). A criação de infográficos pelos alunos estimula-os a encontrar e avaliar informações em fontes confiáveis, além de desafiá-los a apresentar essas informações de forma criativa, contribuindo para o aprendizado do tema em estudo. Em um infográfico digital o

uso de hiperlinks, por exemplo, permite que o aluno trilhe seus próprios caminhos e, à medida que vai escolhendo seu caminho, vai interagindo com o infográfico. Esta interatividade pode variar de um nível mais básico (como clicar em setas de avançar e recuar ou em botões na tela para ver determinado conteúdo) a um mais avançado (como entrar com dados, montar coisas ou simular algo). Com relação à multimidialidade, ou multimídia, além do fato de, no suporte digital, haver a possibilidade de inserir toda e qualquer mídia, 
tem-se como vantagem também o fato de que, segundo Mayer (2005; 2009), as pessoas aprendem melhor através de palavras e imagens do que somente através de palavras (COSTA; TAROUCO, 2010, p. 4).

Infográficos têm sido utilizados para o ensino e aprendizagem de Química, alguns trabalhos relacionados são descritos a seguir.

Hubbard, Jones e Gallardo-Williams (2019) descrevem a criação de tutoriais digitais por estudantes de química para desenvolvimento tarefas/exercícios das aulas de química orgânica. O principal objetivo de aprendizagem da proposta foi criar um tutorial digital com estrutura de infográfico para demonstrar como resolver problemas básicos de química orgânica, e os alunos foram incentivados a usar sua criatividade na produção dos tutoriais e adequá-los ao público-alvo, seus colegas.

Kothari et al. (2019) usa como estratégia de ensino e aprendizagem a produção de infográficos por seus alunos, tendo como norteadora a relação entre a química orgânica e a vida cotidiana (Fig. 1). O objetivo dos infográficos é que os alunos associem o conteúdo das aulas com o seu dia a dia. Uma atividade que envolveu a produção de infográficos foi desenvolvida no contexto de aulas de laboratório de química orgânica. Informações sobre pelo menos uma molécula orgânica presente em um produto de consumo diário dos estudantes deveria compor o infográfico; além disso, o infográfico criado deveria ser visualmente agradável, de leitura rápida, de fácil compreensão. Após receber feedback dos alunos a respeito da atividade, os autores sugerem as seguintes modificações na atividade: aumentar o número de perguntas sobre as informações que irão compor o infográfico (os melhores infográficos contêm mais de três perguntas); orientar os alunos a utilizar fontes confiáveis de informação; criar um espaço de divulgação dos infográficos que proporcione um público real aos alunos, o que deve motivá-los ainda mais.

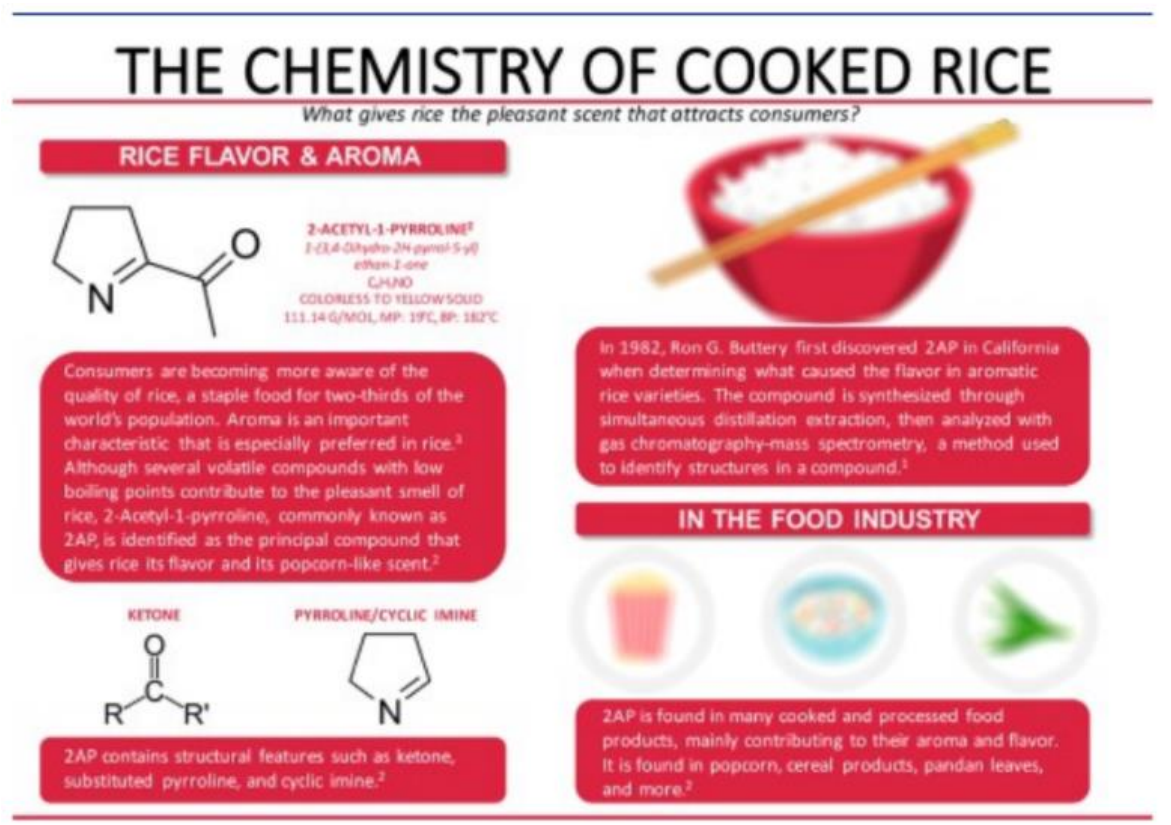

Figura 1 - Infográfico sobre a química do arroz cozido, elaborado por alunos (KOTHARI et al., 2019).

Nesse cenário, criamos uma prática pedagógica envolvendo o estudo da atividade ótica, tema que compõe os estudos de isomerismo e estereoquímica. O objetivo 
deste artigo é apresentar as etapas da prática pedagógica sobre atividade ótica envolvendo a criação de infográficos para o ensino e aprendizagem da estereoquímica no contexto da educação digital.

\section{METODOLOGIA}

A concepção e o desenvolvimento da prática pedagógica foram conduzidos na perspectiva da pesquisa-ação. "Na educação, quando se pretende melhorar a prática, é preciso considerar conjuntamente os processos e os produtos. Este tipo de reflexão simultânea entre processos e produtos constitui, uma característica fundamental da pesquisa-ação (MOREIRA, 2011, p. 90).

A prática pedagógica consistiu no desenvolvimento de atividade de pesquisa, produção de material didático (envolvendo o estudo do tema atividade ótica e o uso de TD) e a auto-avaliação da aprendizagem. A proposta foi desenvolvida (etapa 4) com uma turma de um curso de Licenciatura em Ciências da Natureza, em disciplina de Química Orgânica, ao longo de quatro semanas, de um semestre acadêmico ( $1^{\circ}$ semestre de 2021) cujas aulas foram conduzidas por meio do ensino remoto por conta da pandemia de COVID-19, envolvendo encontros online e atividades assíncronas.

A atividade contou com a participação de 05 (cinco) estudantes, os quais fizeram uso de recursos tecnológicos como: o "Google Drive", as plataformas "Canva" e "Kahoot".

Na prática pedagógica concebida para o estudo da atividade ótica no âmbito da estereoquímica, o "Canva" foi utilizado para a construção de infográficos; e o "Kahoot" como plataforma de exercícios digitais para apoio ao estudo da estereoquímica, por meio questões que serviram como meio de avaliação da aprendizagem para os estudantes.

A elaboração da prática pedagógica consistiu em 4 etapas.

Na primeira etapa, foi realizada uma pesquisa bibliográfica para compreender o que é um infográfico e como construí-lo. A etapa 2 foi dedicada a identificar as características que dão qualidade a um infográfico. A terceira etapa foi a definição do tema - atividade ótica - e a estruturação da proposta. A quarta etapa consistiu no desenvolvimento da prática pedagógica junto aos estudantes, envolvendo a criação de infográficos, sua posterior socialização com os colegas e avaliação.

A avaliação da aprendizagem sobre o tema "atividade óptica", no âmbito dos estudos da estereoquímica, foi realizada por meio de uma atividade na plataforma Kahoot, na qual os alunos utilizaram os infográficos construídos como material de apoio para resolução dos problemas.

\section{A ELABORAÇÃO dA PRÁTICA PEDAGÓGICA}

Os processos de ensino e de aprendizagem de Química desenvolvidos no contexto da educação digital podem viabilizar oportunidades não possíveis em salas de aula convencionais. Entre elas, nessa seção relata-se a planificação, a ação e a (auto)reflexão que nortearam a criação da proposta didática para o estudo da atividade ótica, que compuseram as quatro etapas a seguir descritas.

\subsection{Etapa 1: O que é um infográfico}


Saber o que efetivamente caracteriza um infográfico é um passo importante para estruturar a prática pedagógica. Este conhecimento forneceu subsídios para diferenciar um infográfico de um pôster (ou material educacional semelhante).

Algumas definições de infográficos são, "Infográficos - abreviação de gráficos informativos - são definidos como representações gráficas de informações. Os infográficos funcionam como mais do que uma expressão artística; eles são materiais visuais projetados para comunicar informações que vão desde algo tão simples como um arranjo agradável de figuras a ilustrações estilizadas e complexas animações de dados interativos" (LAZARED; ATKINSON, 2015).

Gráficos informativos (ou infográficos) são principalmente exibições visuais com rótulos e textos que ajudam a explicar o significado de uma ilustração. Em certo sentido, são extensões de fotografias publicadas em jornais com legendas ou recortes que fornecem texto explicativo, mas vão mais além no fornecimento de informações (LESTER, 2011).

A primeira etapa para constituição da prática pedagógica desenvolvida com os estudantes consistiu na apresentação da definição dos infográficos, bem como na apresentação de alguns infográficos previamente selecionados, os quais consistiram em exemplos visuais. Para que o enfoque fosse a compreensão do que é um infográfico e identificação de elementos que os caracterizam foram escolhidos infográficos de temas "gerais", não relacionados à química (Figura 2).

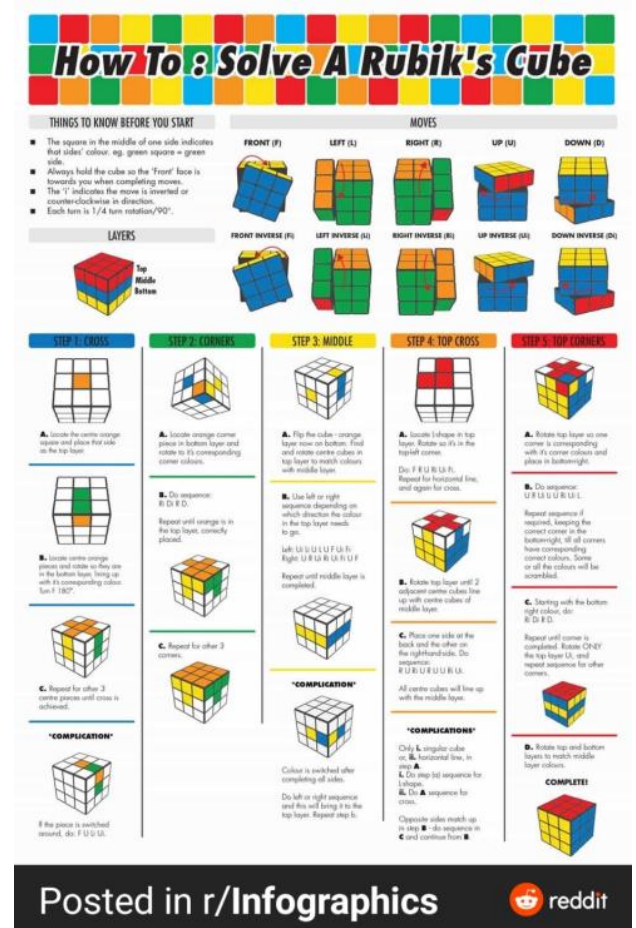

Figure 2 - Um exemplo para entender o que é um infográfico.

(https://www.reddit.com/r/Infographics/comments/n901y6/how_to_solve_a_rubiks_cube/?utm_ medium=android_app\&utm_source=share).

\subsection{Etapa 2: Características que dão qualidade a um infográfico}

As características que dão qualidade a um infográfico foram delineadas a partir da pesquisa bibliográfica. Identificamos algumas características, que deram origem a 5 categorias relacionadas à qualidade de um infográfico, são elas: a mensagem do 
infográfico, a adequação do conteúdo ao público-alvo, a organização e design, a representatividade e a confiabilidade das fontes de informação utilizadas (POLMAN; GEBRE, 2015).

A mensagem do infográfico deve conter informações relevantes ao seu tema, evitando informações não relacionadas. O público-alvo deve ser definido para a elaboração do infográfico, pois influenciará na linguagem utilizada e na relevância geral do infográfico. A categoria organização e design está relacionada à forma como as informações serão organizadas, agrupadas e estruturadas no infográfico, levando em consideração o design e a relevância do design escolhido para a informação que se deseja transmitir. O design do infográfico deve "prender a atenção do leitor" e facilitar a sua interpretação. A representatividade está relacionada à capacidade de obter informações das imagens e figuras utilizadas, bem como à qualidade dessas informações. Alguns aspectos básicos devem ser considerados, incluindo o uso de tamanho de fonte adequado, contraste de cor adequado ou o uso de posições espaciais de uma forma que transmita significado. E a categoria de fonte de dados visa usar materiais de fontes confiáveis.

Com base na Fig.2 a segunda etapa da prática pedagógica desenvolvida com os alunos consistiu em apresentar as características que dão qualidade a uma definição infográfica de infográficos, bem como apresentar alguns softwares/Apps para a criação de um infográfico.

O software recomendado aos estudantes foi o Canva (www.canva.com), por se tratar de uma plataforma de design gráfico gratuita que permite criar infográficos e outros designs a partir de templates. Além disso, o Canva está disponível tanto por meio de página na web quanto como App (disponível para sistema operacional iOS e Android) para dispositivos móveis (smartphones, tablets) facilitando o acesso de usuários e alunos.

\subsection{Etapa 3: Estruturando a proposta pedagógica}

A terceira fase foi a definição do tema - atividade ótica - e a estruturação da proposta, que envolveu a produção de materiais com orientações para a criação de infográficos pelos alunos, a elaboração de questões norteadoras sobre o tema atividade ótica e o design de avaliação da estratégia da proposta didática.

Uma vez definido que o infográfico apoiaria o estudo da estereoquímica, especialmente o estudo da atividade ótica de compostos orgânicos, foram elaboradas questões norteadoras para a construção do infográfico. Sendo elas:

- O que é atividade óptica?

- Quais compostos podem ter atividade óptica?

- Como é possível identificar compostos que possuem atividade ótica?

- Como a atividade ótica pode ser detectada/medida?

- Como são caracterizados os compostos que exibem atividade ótica?

- Como são dados os nomes dos compostos oticamente ativos?

- Qual a importância dos compostos oticamente ativos?

A estrutura do infográfico não precisaria seguir exatamente essa sequência de perguntas. Para ajudar na concepção do infográfico, os estudantes foram orientados a pesquisar e a escolher pelo menos um composto químico que tenha atividade ótica. Este composto químico deveria ser caracterizado no infográfico e utilizado como base para a construção de respostas a algumas das questões norteadoras, tendo ainda seu nome, sua estrutura química, sua aplicação e importância no dia a dia apresentados.

A organização e apresentação das informações/materiais que comporiam o infográfico deveriam ser dispostas de forma que o estudante proporcionasse a melhor 
"narrativa/leitura" do infográfico, a fim de otimizar a compreensão do tema (atividade ótica).

Para orientar os estudantes sobre como usar o Canva, um vídeo tutorial foi elaborado para apoiá-los (60\% dos estudantes não conheciam previamente o Canva). Neste tutorial, foram apresentadas as principais funções do Canva, como usar templates, inserir e deletar elementos e textos, fazer upload de arquivos e configurar cores, tamanho, posição e fontes. O objetivo do tutorial foi evitar que o uso do Canva fosse um obstáculo ao desenvolvimento do infográfico que compôs a proposta pedagógica da estereoquímica.

Por fim, para propor aos estudantes a atividade de criação do infográfico para o estudo da atividade ótica no contexto da estereoquímica, foi orientado que o conteúdo do infográfico deveria ter como público-alvo alunos do ensino médio.

A partir da prática pedagógica que envolve a criação de infográficos digitais, buscou-se proporcionar aos futuros professores de Ciências da Natureza experiências formativas com a adoção de TD. Uma das intencionalidades foi proporcionar a vivência no contexto da educação digital na condição de aluno (ao estudar tópicos da estereoquímica), bem como, na condição de futuro professor, a vivência e experiência da concepção de práticas pedagógicas mediadas por TD, para que estas integrem com naturalidade sua prática profissional.

\subsection{Etapa 4: Desenvolvimento da prática pedagógica}

A quarta etapa consistiu no desenvolvimento da prática pedagógica pelos estudantes, envolvendo a confecção do infográfico e sua posterior socialização com os colegas.

O momento inicial foi dedicado à explicação aos alunos sobre o que era um infográfico, o que diferencia um infográfico de um pôster (ou outro material similar). Em seguida, foi apresentado o tema (estereoquímica: atividade óptica) e contextualizada a atividade de criação de infográficos. Nessa etapa, foram dadas orientações para a busca de materiais, composição dos infográficos, como criá-los (uso do Canva) e apresentadas as questões norteadoras.

Após a etapa de sensibilização dos alunos para realizarem essa proposta didática, eles tiveram uma semana para o desenvolvimento das atividades de pesquisa, que envolveram a escolha do composto orgânico com atividade ótica que seria utilizado na narrativa do infográfico, o aprofundamento de seus conhecimentos sobre estereoquímica e atividade ótica orientado pelas questões norteadoras e a organização e compartilhamento com a turma dos materiais oriundos da pesquisa em pastas do Google Drive. Outra semana foi dedicada à elaboração dos materiais que compuseram o infográfico, bem como a sua criação.

Os infográficos criados foram apresentados por cada um dos estudantes na aula online seguinte, realizada por meio da plataforma Google Meet. Após a apresentação dos seus infográficos, os alunos autoavaliaram os seus conhecimentos na área da estereoquímica, para os quais receberam uma série de exercícios de estereoquímica através do Kahoot para resolução.

A plataforma Kahoot é baseada em jogos e permite a criação de exercícios de múltipla escolha. As questões relacionadas à avaliação desta prática pedagógica foram criadas na plataforma utilizando-se texto (há limite de caracteres) e imagens de estruturas de compostos orgânicos, bem como indicando um tempo limite para as respostas. As questões foram enviadas aos estudantes por meio de um link, durante aula online. Os estudantes foram orientados a responder estas questões utilizando apenas o conhecimento adquirido ao longo da disciplina e utilizando, como material de consulta, o infográfico 
produzido, uma vez que a eles a atividade tinha caráter de autoavaliação. Ao professor, o Kahoot disponibiliza o desempenho de cada um dos estudantes ao responder as questões, permitindo avaliar a aprendizagem obtida por meio da atividade. A média de acerto das questões foi $72 \%$.

Os infográficos criados foram avaliados quanto ao seu conteúdo (escolha da molécula orgânica com atividade ótica, a articulação e o aprofundamento do estudo da estereoquímica balizado pelas questões norteadoras a ela relacionadas), a adequação do conteúdo ao público-alvo, a organização e design (elementos que permitiram avaliar a compreensão, o aprofundamento e articulações entre os conceitos da estereoquímica), a qualidade das fontes de informação utilizadas.

\section{CONSIDERAÇÕES FINAIS}

A utilização de práticas pedagógicas como a apresentada nesse artigo com uso de TD na formação inicial de professores propicia que experiências vivenciadas tragam contribuições na perspectiva dos participantes enquanto estudantes e como futuros professores, promovendo a reflexão de práticas futuras, na perspectiva de investigaçãoação.

A adoção de infográficos no contexto educacional, como no ensino de química, motiva os alunos e aumenta o engajamento durante as aulas no contexto da educação digital. Para melhorar este tipo de prática pedagógica é importante dedicar algum tempo preliminar aos alunos para caracterizar e definir infográficos, apresentar as TD que serão utilizadas (como o Canva), bem como orientar os alunos na sua criação, salientando que nem todo material visual/gráfico informativo é necessariamente um infográfico.

As atividades desenvolvidas pelos estudantes para a concepção do infográfico tiveram como objetivo a aprendizagem sobre estereoquímica, em especial sobre a atividade ótica. Elas envolveram atividades de pesquisa, análise de dados, criação de imagens, e, em especial, a elaboração do infográfico (que requer competências no âmbito educacional, no que tange a aprendizagem do conteúdo estudado, e também na capacidade de apresentar informações e conhecimentos de forma organizada e visual balizadas pelo público-alvo do material educacional produzido).

Além disso, destaca-se a importância da avaliação do infográfico produzido, ou seja, que a atividade não termine com a entrega do infográfico, mas que este e sua contribuição para a aprendizagem sejam posteriormente avaliadas. Sugere-se que essa avaliação, além de aspectos estruturais como planejamento, conteúdo textual, gráficos, citações e design, avalie também a aprendizagem promovida na temática específica estudada durante esse processo de desenvolvimento da proposta didática.

Agradecimentos: Instituto Federal de Educação, Ciência e Tecnologia do Rio Grande do Sul (IFRS), IFRS/Fapergs, IFRS/CNPq.

\section{REFERÊNCIAS}

COSTA, V. M.; TAROUCO, L. M. R. Infográficos: características, autoria e uso educacional. Revista Novas Tecnologias na Educação, v. 8, n. 3, 2010. Disponível em: < https://seer.ufrgs.br/renote/article/view/18045/10633>. Acesso em: 31 out. 2021.

CUNHA, M. I. da. A prática pedagógica do "bom professor": influências na Educação. São Paulo, SP, 1988. Tese (Doutorado em Educação), Universidade Estadual de Campinas, 1988. Disponível em: 


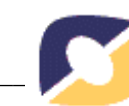

<http://www.bibliotecadigital.unicamp.br/document/?code=vtls000018023\&fd=y $>$. Acesso em: 20 out. 2021.

HUBBARD, B. A.; JONES, G. C.; GALLARDO-WILLIAMS, M. T. StudentGenerated Digital Tutorials in an Introductory Organic Chemistry Course. Journal of Chemical Education, v. 96, n. 7, 2019. Disponível em:

$<10.1021 /$ acs.jchemed.8b00457>. Acesso em: 10 set. 2021.

KOTHARI, D.; HALL, A. O.; CASTAÑEDA, C. A.; MCNEIL, A. J. Connecting Organic Chemistry Concepts with Real-World Contexts by Creating Infographics. Journal of Chemical Education, v. 96, n. 11, 2019. Disponível em: $<10.1021 /$ acs.jchemed.9b00605>. Acesso em: 10 set. 2021.

LAZARD, A.; ATKINSON, L. Putting Environmental Infographics Center Stage: The Role of Visuals at the Elaboration Likelihood Model's Critical Point of Persuasion. Science Communication, v. 37, n. 1, 2015.

LESTER, P. M. Visual Communication: Images with messages. California: Wadsworth Publishing Company, 2011.

MOREIRA, M. A. Metodologias de Pesquisa em Ensino. São Paulo: Editora Livraria da Física, 2011.

MOREIRA, J. A.; SCHLEMMER, E. Por um novo conceito e paradigma de educação digital onlife. Revista UFG, v. 20, 2020. <https://doi.org/10.5216/revufg.v20.63438>. Acesso em: 13 out. 2021.

NICHELE, A. G.; CANTO, L. Z. Uma prática pedagógica para o ensino e aprendizagem de química ambiental. Revista Novas Tecnologias na Educação, v. 18, n. 2, 2020. Disponível em: < https://seer.ufrgs.br/renote/article/view/110297/60051>. Acesso em: 20 out. 2021.

POLMAN, J. L.; GEBRE, E.H. Towards Critical Appraisal of Infographics as Scientific Inscriptions. Journal of Research in Science Teaching, v. 52, n. 6, 2015. Disponível em: <10.1002/tea.21225>. Acesso em: 11 set. 2021. 